\title{
A Feasible Rural Education System
}

\author{
Lincy Meera Mathews \\ Assistant Prof, Department of ISE,MSRIT \\ M S R Nagar, Bangalore, \\ Karnataka, India
}

\author{
Dr Bandaru Rama Krishna Rao \\ Senior Professor, School of Information Technology and \\ Engineering, Vellore Institute of Technology \\ University, Vellore, Tamil Nadu
}

\begin{abstract}
The education system in rural and semi-rural areas of developing and underdeveloped countries are facing many challenges. The limited accessibility and challenges to the education are attributed mainly to political, economic and social issues of these underdeveloped countries. We propose a "Feasible Rural Education System (FRES)" based on Ontology and supported by Cloud to enhance the accessibility to education in rural areas. The system has been proposed incorporating the FOSS approach.
\end{abstract}

Keywords- FRES; Education; FOSS; Semantic Web; Ontology; Natural language processing; Cloud computing.

\section{INTRODUCTION}

In developing countries like India, the rural and village schools form $87 \%$ of the total schools, of which $90 \%$ are run by the government with financial aid and rest of the schools are unaided [1]. These schools offer education in four phases: Primary, Upper-primary, Secondary and the Higher Secondary.

Though the literacy rates in developing countries have been steadily increasing in higher education system (which includes educational and vocational training), the same is not noticed in the Primary and Upper-primary education in rural and semi-urban areas. Various initiatives had been taken up by the Government of India to support Education in rural areas by bringing in various technologies and through the usage of internet. The role of Information and Communications Technologies in education can be dispersed into manners [6].

- Alternative instructional delivery systems such as radio, educational $\mathrm{TV}$ and audio visual communication.

- Computers and computer based system for instructional delivery and management; use of multimedia and internet/web based education.

As an initiative for the former mode of communication, EDUSAT was launched in September 2004, at a cost of USD 20 million. India's first Education satellite was dedicated. However it has failed to provide any speak able impact in rural areas. The problems attributed to this were previously recorded lectures, non-interactive nature of sessions, not formed for as per students learning capability.

As for the latter, the government has initiated an Internet Based Continuing Education. The components are comprised of online learning materials, online Academic counselling, online assignments and projects and online collaboration. To help back all the state government ICT education initiatives, in May 20, 2006, the government of India, Ministry of HRD, Department of Secondary and Higher Education had issued an order for the implementation of Broadband Connectivity in all secondary schools. To accelerate the progress of education in rural areas, we take the help of the free and open source software (FOSS) movement. The FOSS has originally begun as an intellectual movement for development, modification, ownership and redistribution of software managed by a community of programmers. We suggest that the principles of FOSS namely transparency, collaboration, openness and coownership can be introduced in our education system in providing accurate, accessible and free education resources.

\section{LACUANES IN RURAL EDUCATION SYSTEM}

A typical rural education system contains three main components namely: Teacher, Student and Infrastructure [2].

\section{A. Student}

In rural scenario, student speaks his native language more fluently, demanding communication for learning in local language. A student in rural area faces more challenges in daily life as compared to his counterpart in urban areas, to name few (i) lack of commutation to schools situated far off from villages, (ii) playing in streets, want of setup area meant for play (iii) studying under street lamps, want of electricity at home, (iv) lack of good curriculum or educational material, (v) lack of full-pledged laboratory or library facilities etc. In essence, priority for rural student is to survive for the day rather than look and work for a better future. The governments of developing nations aim to bring quality education to these rural students so that they could compete with their urban counterpart. However, this becomes difficult, since, the urban schools have access to top-class teachers, laboratory and library facilities. Therefore, the needs to be addressed for rural students are as follows:

- An interesting and challenging representation of free education material, so that attention of the student holds.

- Communication in learner's language.

- Limited dependence on teacher's instruction and on non-availability of other modes of learning.

- More interaction with students of other schools of the same curriculum. 
- Up to date and accurate representation of curriculum

\section{B. Teacher}

A teacher plays the most impacting role in the rural education system. A teacher forms the root of the system on which students, learning resources and technologies are dependent. Without the teacher, the student stands to gain a very limited knowledge. The learning resources and the new technologies cease to play any role if teachers do not use the facilities. The learning resources will not be reviewed if the teacher fails play an active role in the education system. The more effective the teacher becomes, the better the quality of learning by students. However, the challenges faced by teachers of rural and semi urban in terms where technology can play roles are as follows:

- The large gap between rural and urban technology in facilitating teaching and learning process.

- Limited availability of facilities like study materials, language friendly multimedia.

- Very less or non- availability of resources for accelerated and quality learning.

- Huge cost involved in procuring and maintenance of infrastructure- mainly software and hardware.

- Lack of communication between schools handling the same curriculum, hence shortage of updated information and mentoring programs.

\section{Infrastructure}

The basic infrastructure required can be divided into consumables products and non-consumable products. The consumable products mainly are stationery items such as exercise books, pens, pencils etc and the non-consumable materials are the curriculum, learning aids, visual aids and technological equipment's. The dearth of non-consumable products can be met by present day technologies. The various factors that need to be addressed in this context are as follows:

- Free availability of resource materials in the form of text, video or audio classes.

- An effective teaching guide to support the teachers and learners.

- Challenge based or game based learning curriculum that can hold the attention of learners.

- An effective educator system that can take care of mentoring and supporting of rural educators.

- Availability of technology (software and hardware) without the maintenance and cost issues.

- A user friendly interface preferably in the local language of the user

- Low cost systems and lab facilities.

Various other factors like political, male to female ratio, economic reasons exist [3]. However factors where technology can play a role and help alleviate the hurdles should be addressed in this current era.

\section{FOSS IMPACT IN EDUCATION}

The Free and Open source movement was begun by a community of programmers to remove or decrease restrictions on collaborative development, distribution, ownership and redistribution of software [5]. This however got noticed and the principle is being applied by various researchers and academic communities in various domains. The values that the FOSS movement promotes are openness, transparent collaboration and co-ownership. All these values need to be adapted into the education scenario.

\section{A. Openness}

Openness in FOSS environment is to have open access to the source code. In education, openness leads to free access to curriculum and pedagogy. Currently information related to curriculum and pedagogy is available only to the selected few. Though governments provide may Open-Courseware resources such as Indira Gandhi National Open University (IGNOU), NPTEL (National Programme on Technology Enhanced Learning ) and the CEC ( Centre for Education and Communication ) repository in India, they are not entitled for changes by others to suit their curriculum, and faces the following challenges:

- Information retrieval works on the basis of queries. The relevance of data is directly proportional to the completeness of a query. The information retrieved is dependent on the learner's query.

- Trust factor of information retrieved is yet a widely researched area. The user has to decide on the accuracy and completeness of information.

- There is no guidance in the flow of information or in the method of learning process. The user or reader must decide on the flow of information to be read as there is no connection between the information. If the student begins on a certain topic, he must be guided to its prerequisite information.

- No guidance is available when the student scours through lengthy material or tutorial. The online tutor is absent. She/he does not have any interaction with subject matter expert or any answering system for his queries \& doubts.

- The maturity of the user is also of utmost importance. Her/his understandability of the instruction, level of language proficiency, and the grasping power of an individual all plays a role in effectiveness of the information.

\section{B. Collaborative development}

This in terms of software relates to the development of code by several professionals interested in the tool or software. They decide to do changes so that it helps in their application.

With education, collaborative development has been interpreted as a transparent process for formulation of educational policy, syllabi and content related to the curriculum or course. The hurdle here lies with the transparency process. The limitations of applicability of 
transparent collaboration in education may be attributed to the following reasons.

- $\quad$ There exist no common policy and decision makers. There are different methods of learning tools. Some schools believe in sending work home. Some work on completing at school premises

- There is always a change in curriculum delivery for secondary education. Textbook variation, selection of portions and time of completion causes difference in the delivery of curriculum.

- Many universities have created their digital repositories for the benefit of students. This however has been a good initiative for the students of the respective schools. All different kinds of tools are being used for updating like PPT, text, audio, video or word. Updating of resources requires understand ability of the underlying software. It poses restriction to authors of various domains.

\section{Co-ownership}

In FOSS, Software can be freely distributed without licensing fees. In education the main stakeholders are the students, teachers, parents and the institution. Ownership relates to the freedom of access and an equal influence over all intellectual artefacts used in the education system. Here again the access and empowerment of curriculum lies in the hands of the select few, who are eligible for the resources and not those few who are in search of knowledge. Faculties do not have access to better materials from various guides. They lack support from domain proficient members and no knowledgeable tools. To bring co ownership to education would mean able to modify and reuse the repositories.

Creativity also has been the other important aspect where the users who have laid the FOSS foundation have encouraged. In all its forms, creativity is the spirit in FOSS. This also must be followed in areas of education too. Tools that enable creativity must be created and used to provide various challenged based learning. The user plays a very important role in creativity. Incorporating the Bloom's taxonomy is one of the major hurdles that are faced by curriculum developers.

\section{Semantic Web Based Education System}

\section{A. Use Case Scenario}

Understanding the shortcomings and the difficulties of a student from a rural background is important aspect to consider in the teaching learning process. Since the system can be categorized as an e-learning space, all the characteristics of classroom learning if not more must be incorporated into the system. The rural education system has basically three entities: Domain model, student model and Facilitator's model. Three requirements of the Semantic Web Education System for three different entities are discussed below.

\section{1) Student requirement:}

- Student needs a guide as he sits through the learning system. She needs an interactive system that guides him through his learning process
- Her preference of the learning style :Audio, Video, Text or Incorporation of all formats

- The dynamic flow of learning material that suits his understanding capability. She does not have to go through the entire material but that suits his need of knowledge

- Learning material presented depending upon his cognitive learning style

- A good and friendly user interface

- Student data to be stored with respect to his interest, his learning mode etc

- High quality information

- Student community

2) Domain requirement

- Storing of content's metadata or its relevance in the learning repository

- Structure definition: Organization of each content material or the learning sequence of the learning material

- Format of the resource material like video. Website , Audio etc

- Reusability of the content

- Dynamic updating of the content

- Quality assurance

- Automatic of display of Content depending on user's input

3) Facilitator's requirement:

- Uploading of resource material in any format

- Updating of content

- Questionnaire in relevance with the content

- Evaluation procedures

- Guiding of students online or offline

- A secured and an user friendly interface

\section{B. Ontology Support}

Ontology can be used for knowledge representation with respect to each domain [4]. Domain ontology has its advantages. Firstly it allows reuse, updating and sharing of ontology between ontology friendly environments. Secondly it has its formal structure which makes it easy to extract and obtain knowledge representations. The courses or resource material can be divided into declarative or procedural knowledge. The declarative knowledge represents the factual and conceptual knowledge while the procedural knowledge represents action sequences and problem solving procedures. The objective behind using ontology is to facilitate a structured knowledge which helps facilitate reasoning and help provide the best learning session as per learners need. 
We present here the architecture (Figure 1) of ontology supported education system. The ontology supported web based education system has basically three components. They are the facilitator, learner and the data repository. The data repository forms the ontology supported data for the student and the learning documents. The facilitator's role is to support in content design and providing student support. The learners form the student as well as faculties of rural schools. They are the actual beneficiaries of the system. The web based system is then deployed on to a dedicated cloud for education purpose only. The web based application is in the form of centralized web-based applications. One instance of an application hosted in the cloud is cheaper and easier to manage. Upgrading of the application which is to be done often due to development of educational content has to be done often.

To define the ontology, OWL-DL (Protégé Editor has been used. The curriculum developed was included for a single course. The proof of concept will be deployed in Amazon, where it has its Elastic Compute Cloud (EC2), a web service that provides cloud-based resizable computing capacity for application developers.

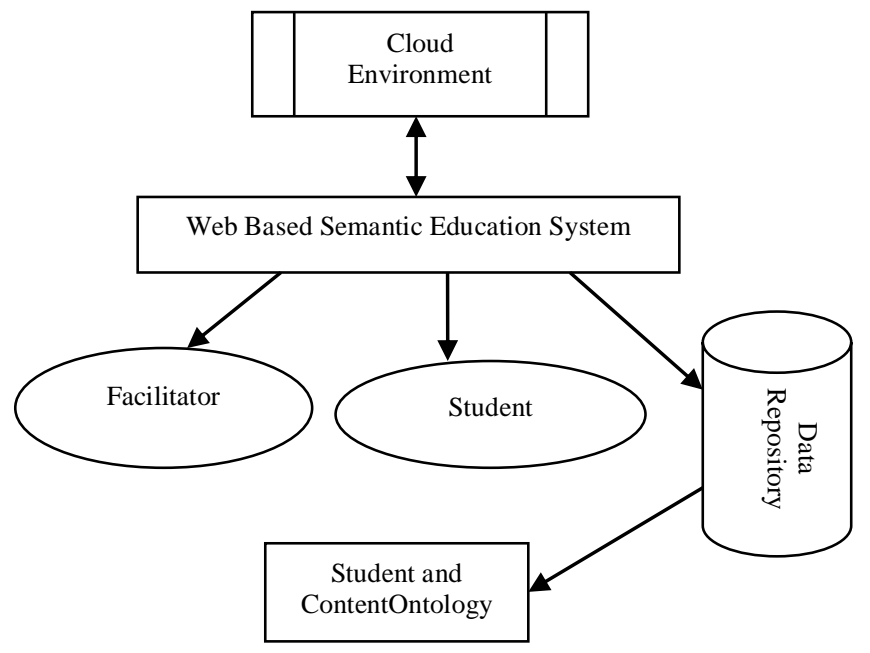

Figure 1: Architecture of Rural Education System

\section{1) Domain Model}

The courses are being represented in the form of ontology. The ontology as shown in figure 2 has been organized as follows. The definition class has been subdivided into mainly three sub classes. The definition class is being defined by the source, Content author, last_modified_date and the learning objectives. The definition class exists for contents updated into the domain model. The learning objectives compulsorily follow the objectives as per Washington accord. The source of content will be updated as a pair value of Source and contented. The content_ID acts as the sequence no which denotes the sequence no in which the content is to be presented.

The format class is linked by its various subclasses by the relationship of "for_a_particular". The individual contents could be an image, audio, video or text. The relationship between these various subclasses follows an OR relationship. The contents can be of more than one format but not necessarily all formats. The text data can be further categorized as PPT, .doc or Pdf formats. The PPT might be supported with audio also.

The structure denotes the actual content and details for rendering of content. The subclasses are the content, FAQ's, and test. The content is further divided by its purpose and aim. It can be classified as definition, principals, advantages, application etc. The content is also rated depending on its difficulty level. The content can be rated as topics that come under surface learning and deep learning. The surface learning can be described as the using low level cognitive skills and minimum effort to complete the course requirements. The deep learning involves understanding, engaging in higher level cognitive skills. The student should be able to think conceptually about a topic. The content is being identified by its content_id which will be given as input for the sequence _no subclass. The sequence _no subclass will be related to the prerequisite subclass. The prerequisite states that content to be mastered before the actual content is to be read. The test subclass relates to the content that is to be used to evaluate the students. The evaluation content could be objective or subjective type of questions. The structure class also maintains a FAQ's. The FAQ's will be referred when a student poses a question. The question will be matched against the FAQ pool.

OWL-DL (Protégé Editor) has been used for defining the ontology .The document ontology is being represented as an Onto Graph. Figure 3 states the object properties between various classes. The relationships indicate the functional dependence between various classes. All classes have direct dependence to its subclasses. However certain classes have dependencies to other disjoint classes. One of the functional dependence indicated is the prerequisite. This states that content will have a prerequisite. The inverse relationship is built automatically. In the above example, a prerequisite exists for all content.

\section{2) Student Ontology}

The lack of physical educator must be compensated by the system. Said in other words, the system must understand the need of the students and present the course that suits his learning style. The student background information is stored to help navigate and select the right learning style for the student. The profile includes his pre schooling, his language competency, his reading skills, his attention span etc. The preference of his learning style is also recorded for the benefit of the student. The different learning style can be categorized into visual learners, auditory learners, reading /writing learners, and kinaesthetic learners.

The cognitive learning style defines the cognitive characteristics that the student possesses. The Cognitive characteristics can be categorized as brainstorming followed by session or vice versa. It is believed that certain students need facts as to why certain content must be mastered. The evaluation procedure is recorded in the subclass in evaluation metric.

The metric store scores as against to each content for each student. As they complete the test in accordance to the content referred, the metric is updated. The description of the individual can be specified by using the individual description view. 


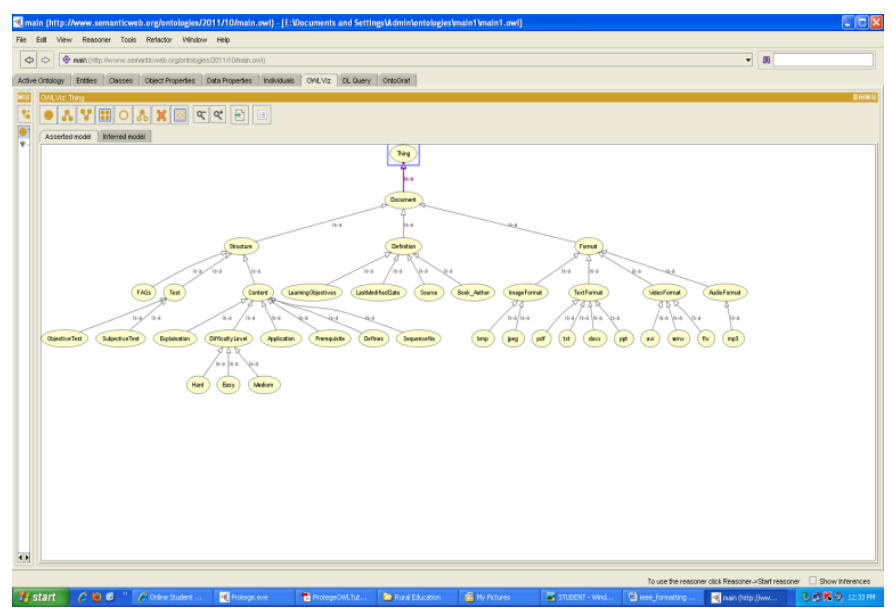

Fig. 2 OWL Viz representation of Document ontology

\begin{tabular}{|l|l|l|}
\hline Domain & Object Property & Range \\
\hline Definition & Depends_on & Content \\
\hline Content & Requires & Prerequisite \\
\hline Sequence no & Is_based_on & Content \\
\hline Format & For_a_particular & Content \\
\hline Test & Evaluation & Content \\
\hline FAQ's & For_each & Content \\
\hline
\end{tabular}

The year to which he belongs can be added. Restrictions can be added by selecting the property assertion view. For example, he belongs to any year but value for year must be less than four. Using the equivalent class tab, conditions can be asserted. For example: Student and belongsto some integer $[,=" 4$ "^^integer $]$ hasdetail some profile. The subclass feedback provides the mentors or facilitators a timely statement so that the facilitators can improve the course. The student ontology has been shown in Figure 4. The relationship defined between the various subclasses has been shown in figure 5 .

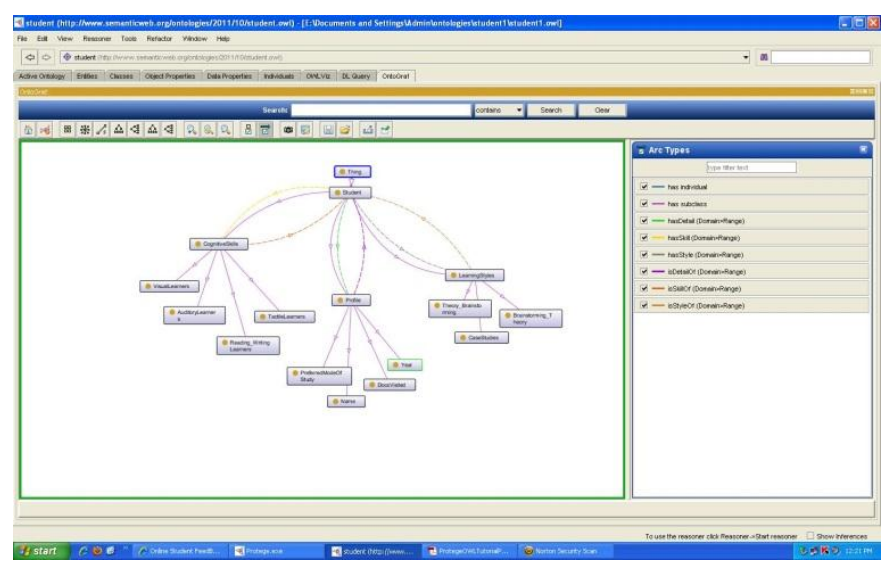

Fig. 4 Onto Graph representation of Student ontology

\begin{tabular}{|l|l|l|}
\hline Domain & Object Property & Range \\
\hline Profile & Has_skill & Cognitive Skills \\
\hline Profile & Has_style & Learning Style \\
\hline Profile & Has_some & feedback \\
\hline \multicolumn{2}{|c|}{ Fig. 5 Onto Graph representation of Student ontology }
\end{tabular}

\section{3) Facilitators Model}

Facilitators should be able to enter any of the content in any formats as per convenience. The tutorials can be used by faculties also for their benefit. The tutor when online will have the capability of clearing the doubts raised by students. The questions with its answers will enter the GAQ's pool. The domain specialized author will be authorized to verify and rank the content. The evaluation metric can be for assessment of student's performance. It also indicates to which level of learning the student has progressed.

A domain expert is involved to develop the course into various modules. With those various modules, ontology has to be constructed. Each module or content must be mapped with the learning objectives. The FAQ's must be evaluated for it content by the domain expert.

\section{Design of Flow}

Student:

- As a student logs onto his system, his profile will be considered.

- As he request for certain content, his preferred learning style and cognitive style will be taken into account.

- Depending on his completion of previous sessions, topics will be presented to the user.

- Brainstorming session will be followed by content if his preferred style of cognitive learning is concrete generic type

- If questions are asked, he can directly pose the question to the facilitator

- If facilitators are offline, the question will be matched to the existing FAQ's

Facilitator

- The author can upload and modify the existing content

- Answers to questions of users should be completed

- Domain experts must be able to rank the content and verify the same.

- Provide the right sequence of rendering of content

\section{CLOUD COMPUTING FOR RURAL EDUCATION}

Once the system has been developed, it should be accessible to the rural community. For this, the Web based system must be deployed on the Cloud. The lacunae in infrastructure, student and teachers in the rural community can be offset by the benefits of deploying on Cloud [7].

- As the application is run in the Cloud and not on the desktop PC, the desktop PC doesn't need the processing power or hard disk space demanded by traditional desktop software. Hence the client computers, i.e. the rural schools systems can be lower priced, with smaller hard disks, less memory, more efficient processors, and the like. There is no requirement of a CD or DVD drive, because no software programs have to be loaded and no document files need to be saved at the user side. 
- Computers in a Cloud computing system will boot up faster and run faster, because they'll have fewer programs and processes loaded into memory

- Cloud computing greatly reduces both hardware and software maintenance. With less hardware (fewer servers) necessary in the schools, maintenance costs are immediately lowered. As to software maintenance, as cloud applications are based elsewhere, there's no software on the school's computers for the IT staff to maintain.

- $\quad$ The need to access any particular software in the cloud now becomes less expensive. Software licenses need not be purchased for each system. Even if it costs the same to use web-based applications as it does similar desktop software (which it probably won't), the maintenance staff have saved the cost of installing and maintaining those programs on every desktop.

- When the app is web-based, updates happen automatically and are available the next time the user logs in to the cloud. Whenever the student accesses a web-based application, the updated version of the application is being downloaded.

- All contents are instantly available from whichever community schools have been registered with the education system

- The documents can be accessed simultaneously; the modifications done by one user is automatically reflected by which the other users can see onscreen.

\begin{tabular}{|c|c|}
\hline Phase & Activity \\
\hline Requirements & $\begin{array}{ll}\text { - } & \text { Define Objectives } \\
\text { - } & \text { Feasibility study } \\
\text { - } & \text { Validate scope of the project } \\
\text { - } & \text { Understand Key processes } \\
\text { - } & \text { Study the Application Landscape } \\
\text { (Environment) } \\
\text { - } \quad \text { Understand the key requirements } \\
\text { List the risks, dependencies \& } \\
\text { impacted components }\end{array}$ \\
\hline $\begin{array}{l}\text { Planning } \quad \& \\
\text { Analysis }\end{array}$ & $\begin{array}{ll}- & \text { Design a Rollout plan } \\
\text { - } & \text { Define test cases } \\
\text { - } & \text { Design Document } \\
\text { - } & \text { Validate the capacity planning of } \\
& \text { the servers } \\
\end{array}$ \\
\hline Implementation & $\begin{array}{l}\text { - Setup POC environment for pilot } \\
\text { application and build platform } \\
\text { - } \quad \text { Test the Upgrade \& amend the } \\
\text { target design as per results } \\
\text { - } \quad \begin{array}{l}\text { Assess any performance and } \\
\text { availability related issues. } \\
\text { - Revisit the design and update as } \\
\text { needed } \\
\text { Prepare the Master rollout } \\
\text { schedule }\end{array}\end{array}$ \\
\hline
\end{tabular}

Fig. 6 Life Cycle of Deployment of system on Cloud
The web based education system will be implemented through various stages as shown in figure 6.

In the requirements phase, the feasibility study is to be carried out. The number of schools, users including the students and faculty should be assessed. The key processes such as content loading and updating; student updating of assignment downloading of contents, availability of software pertaining to the format of the content to be downloaded should be assessed. The scope of the project should also be analyzed.

This includes the content will be formed for how many courses, the formats available for a particular content, the no of users and the number of schools accessing the web based application. The risks also has to be accessed which can occur due to disagreement in the content of a course. It can also occur due to loss of information, change of author etc .In the analysis and design phase, the various components for students, faculties and authors have to be tested. Phase wise testing will take place. The web based education system will be uploaded on a server however the capacity required as per users, data should be considered and decided.

The implementation phase will be for deciding the scope of proof of concept. The border of environment will be formed. Here the number of users, schools, and the content will be worked for the initial POC. The entire POC will be revisited depending on the feedback and issues that arises in the design and planning phase.

\section{CONCLUSION}

The paper aims to present in details the components of a rural education system. The drawbacks and the challenges have briefly discussed. The technological solution to fill the lacunas of the present rural education scenario was briefly explained.

The ontology has been used for representing the knowledge repositories with respect to students and content. By deploying the web based semantic education system on to cloud help address several other issues regarding the rural education scenario.

\section{REFERENCES}

[1] T.Coladarce, Improving the yield of Rural Education Research: An Editors Swan Song, Journal of Research in Rural Education, 2007, 22(3)

[2] S.Chakraborty and Bhatacharya, Shishak: An Intelligent tutoring System Authoring tool for Rural Education", Information and Communication Technologies \& Development, 2007 ICTD 2007,pp1-10

[3] M. Hall, The Challenges for India's Education System, Chatham House, Asia Programme, April 2005, ASP BP 05/05

[4] BiswanathDutta and Devika P Madalli, Ontology Supported Personalized E-learning repositories, University of Trento, August 2009, Technical report, \#DISI-09-052

[5] S.Babu, FOSS Movement and its impact education, CSI Communications, Knowledge Digest for IT community, Issue No 6, Sept 2011, Pp 19-22

[6] A Kumar and R Rajendra, Perspectives on ICT Education in India",

[7] Micheal Miller, Cloud Computing, 2008, Edition 